\title{
Fuzzy Quality Function Deployment in Online Shopping Websites - Literature Review
}

\author{
Ashish K. Sharma ${ }^{1}$, Sunanda Khandait ${ }^{2}$ \\ ${ }^{1}$ Research Scholar, Dept. of Computer Science Engineering, PIET, Nagpur, India \\ ${ }^{2}$ Professor, Head of IT Dept., KDK College of Engg., Nagpur, India \\ 1ash5000@rediffmail.com, ${ }^{2}$ prapti_khandait@yahoo.co.in
}

\begin{abstract}
Today, an effective website design has emerged as a thing of main concern for online shopping businesses and thus the companies involved in the online shopping businesses are aspiring for well-designed websites. In the past, several methods have been reported but they proved unproductive as they failed to handle the decision making involved in the process to evaluate the customer needs efficiently. Thus to cope up with the issue, the paper considers QFD approach as it a customer driven process that strongly assists in guiding the design decisions. The purpose of this paper is to explore the issues that have resulted in the decrease of satisfaction rate of users, analyze the problems with the methods used and propose effective solution through the literature review. The contribution of this paper is manifold. First, it explores QFD at length and evaluates its applicability for effective design of online shopping websites. This helps users understand the decision making capabilities of QFD. Second, it highlights the limitations of QFD approach in handling the vague and imprecise data that arise due to the inherent crisp approach and subjectivity involved in the QFD approach. Finally, the paper proposes fuzzy integration with QFD to deal with the uncertainty and vagueness involved in the QFD process for improved decision making and more precise results leading to effective design of online shopping websites. The literature review is based on information from various research papers, tools and web sources.
\end{abstract}

Keywords: Online Shopping; Websites Designing; Quality Function Deployment; QFD; Literature Review; Crisp; Fuzzy

\section{Introduction}

Owing to the widespread use of the Internet, online shopping has emerged as a very popular mode of shopping. Online shopping was invented and pioneered by Michael Aldrich in the UK. Online shopping is far better than traditional shopping as everything is available to us at our door step just with the availability of internet [1].The popularization and rapid development of the Internet has fostered the growth of online shopping leading it to become an important new channel for consumers to make purchases [2].There are several factors that have contributed in the growth of online shopping - busy lifestyle, high disposable income, awareness of products, rising computer educational level, increased usage of internet, easy to find the review of products [3]. Although online shopping has become a growing new trend, consumers are still not very satisfied with the current design and operation of the shopping websites [4]. As a result, the Internet users' rate of satisfaction has declined since online shopping has become an important consumer option [2]. There are numerous factors that form the basis for successful online shopping businesses -ease of operation, friendly user interface, high and quick quality services, appealing and informative design of website etc. [3]. Amongst these factors, website design carries more significance as it acts as an implementation vehicle for the successful online business. Website design plays an important role in gaining the user satisfaction 
which in turn leads to the success of business. A well designed website helps reinforce the firm's brand equity, while a poorly designed website can devalue the established brand equity [5]. Thus, businesses are striving hard for well-designed websites.

Over the years a pool of techniques has been employed for website designing but none of the techniques proved much effective. Despite the plethora of articles and books on how to build "effective" websites, very little actual research has examined the impact of various website design features [6]. As a result, website designing for the online shopping websites has become a fertile area for researchers. Recently the use of Quality Function Deployment (QFD) in designing online shopping websites has been reported. Albeit QFD can generate better results but it suffers from the problems like - use of linguistic expressions and crisp values [7].These crisp values cannot reflect the imprecision or vagueness and yields inconsistency in the results [8]. The issue can be overcome by applying fuzzy concepts. To this end, through the literature review this paper makes an attempt to address the aforesaid issues and discusses the urgent need of fuzzy QFD for effective design of online shopping websites. The focus of this paper is to examine the recently proposed QFD approach in designing online shopping websites; highlights the issues involved and then propose effective solution to address the issues. In this regard, the paper reviews the current issues involved in online shopping websites and underlines the various methods used and analyzes the recently applied QFD approach. Thus, the literature about the associated fields QFD, QFD in Websites Designing, Websites Designing in Online Shopping, QFD in Online Shopping Websites, Fuzzy Concepts, and Fuzzy-QFD find relevance in the paper. Finally, through the literature review, the paper proposes the fuzzy integration in QFD for more improved results that can lead to effective design of online shopping websites. The literature review is based on the data collected from various research papers, tools and web sources. The work is expected to provide valuable data and promote further research into website designing of online shopping websites.

\section{Issues in Online Shopping Websites and Techniques Used}

Today, the websites have become a main source of any type of information. Websites can influence several aspects of the value proposition, as they enable direct interaction, have virtually no variable costs, and compared to traditional media, are more flexible and superior in targeting the users [9]. Thus, business enterprises - from multinational conglomerates to solo entrepreneurs are staking their presence in the Internet, all poised to become pioneers in what promises to be the frontier of electronic commerce [10]. As a result, there has been a considerable rise in the number of online shopping websites. Albeit there has been a tremendous growth in online shopping, the level of user satisfaction has descended largely. The reason for this is inefficient design and operation of the shopping websites. A well designed website acts as an implementation vehicle for the successful business as it symbolizes customer satisfaction. Thus, organizations across the world are paying increasing attention to the website design [11]. Moreover, as businesses attempt to exploit the boom in electronic commerce and marketing over Internet, issues of website design and technology usage have become even more critical. In addition, websites require delving into various aspects related to development, maintenance and promotion. Because, the development, maintenance and promotion of a website require a high investment, but the value and end-benefits associated with it are not always materialized [12]. Moreover, there have been cases when some of the websites had to be revamped or redesigned as they failed to deliver because of inappropriate design. The TV3 website has been revamped and redesigned four times in the span of eight years [11]. An effective and efficient web design is the need of hour for the businesses involved in online shopping as it signifies the satisfaction factor and success of the businesses. 
Several techniques for website designing have been employed like cooperative design, user-centered design and participatory design etc. but none of the techniques proved much effective. A lot of research so far has addressed various approaches so as to achieve this understanding. Website development projects incorporate a high-risk parameter. Some efforts have been made by IT professionals to deal with this issue and lessen the risk related with it by adopting suitable design, development and deployment methodologies. The user-centered design focused on the need for designers to base their rationales on an understanding of the work domain to be supported. Prior to that the work in cooperative design, user-centered design and participatory design has emphasized the role of userparticipants in treating work context as an empirical source of design rationale and has addressed some of the user work domain problems facing web designers, principally the problems of incorporating workplace expertise into the design process [12]. Other research efforts on web design development refer to the conception of usability. Many researchers have enumerated some of the difficulties of incorporating usability into the design of websites [13]. A specific process for initiating, developing and launching web pages that incorporates usability techniques at several points in the development cycle is suggested by [14]. The usability and communicability problems for transactional web applications were discussed by [15]. The online shopping behavior is a key to successful development of a B2C e-commerce is highlighted by [16]. Recent studies have reported the use of QFD in this regard and the results showed that QFD proved quite effective for the designing of online shopping websites.

\section{Quality Function Deployment (QFD)}

QFD is one of the most important methods to satisfy the customers and to transform customers' requirements into design aims [17]. Yoji Akao described QFD as a "method to transform user demands into design quality, to deploy the functions forming quality and to deploy methods for achieving the design quality into subsystems and component parts, and ultimately to specific elements of the manufacturing process" [18]. The design benefits of QFD are - fewer and early design changes, less time in developments, fewer start-up problems, lower start-up costs, fewer field problems, more satisfied customers, and the identification of comparative strengths and weaknesses of products with respect to competition [19]. QFD is based on the widely used Four Phase Model, which focuses on the quality deployment part of Akao's comprehensive QFD framework. The four phases represent product planning, component planning, process planning and production planning [20]. The QFD comprises several different parts or rooms, which are sequentially filled in order to achieve an actionable translation from requirements into characteristics [21]. The major vehicle through which QFD is implemented is House of Quality (HOQ). It is the central tool of the QFD which analyses customer requirements in detail and translates them into the developer's language [22]. The diagram is known as HOQ because its architecture is similar to a house. Like a normal house (which has foundation, walls and roof), HOQ has a number of components, which are:

- Customer Needs

- Technical Requirements

- Relationship between Customer Needs and Technical Requirements

- Relationship among Technical Requirements

- Prioritized Customer Needs

- Prioritized Technical Requirements

Of the above components, prioritized technical requirements form the foundation of the house. Customer needs and prioritized customer needs form the walls. Relationships between customer needs and technical requirements form the main body of the house. Relationships among technical requirements form the roof of the house. Technical 
requirements form the ceiling of the house. The general architecture of the house has been shown in Figure 1 [11]. Over the years, QFD has found wide acceptance. It started off with the manufacturing but gradually got accepted and applied in several distinct areas, recent being the websites design and development.

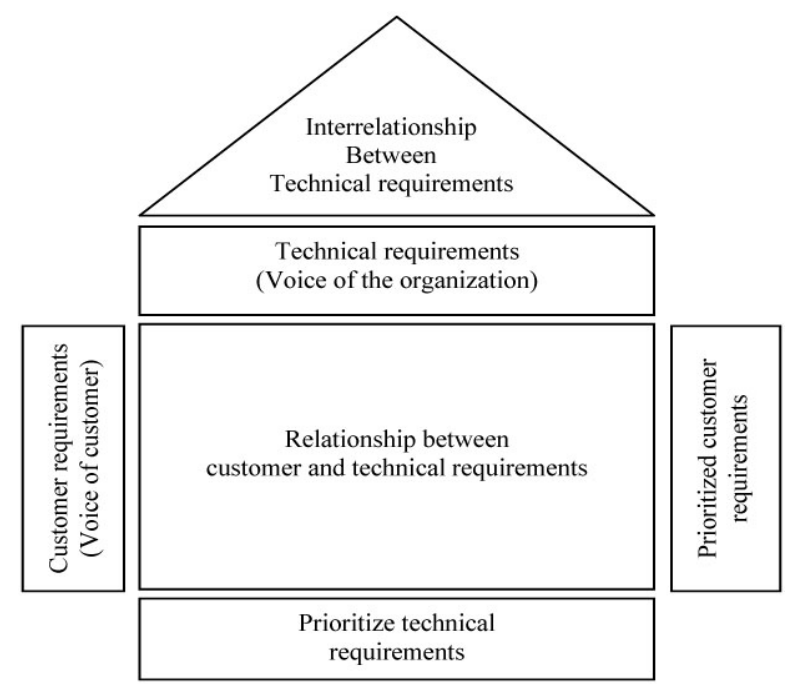

Figure 1. The Basic Building Blocks of House of Quality - QFD

QFDs functions had been expanded to wider fields such as design, planning, decisionmaking, software systems, healthcare systems, engineering, management, teamwork, timing, and costing. Essentially, there is no definite boundary for QFD potential fields of applications [23]. Reference [2] focused on examination of the online shopping website and utilized QFD to attain an understanding of customer quality needs, quality elements, and the relationship between them. Reference [24] have investigated multiagent service quality problems in the area of airport management and proposed the use of the multi-layer QFD model to compromise the requirements of both airline companies and passengers to ensure generality and sustainability of quality implementation. Reference [25] has introduced Software Process Improvement (SPI) and QFD with Capability Maturity Model Integration (CMMI). Reference [26] has presented an evaluation of software process models for the development of QFD software. Reference [27] worked on railway project via web surveys approach to extract the software requirements. Reference [28] proposed a QFD and Functional Analysis (FA) based eco-design method to systematically generate design concepts for the reduction of environmental impacts. Reference [29] has showed a software development process for QFD automation, integrated within a Product Data Management (PDM) platform. The software package improved the speed of the whole design process through automation of tasks. Reference [30] has proposed an e-Business planning framework which links both in strategic and operations management by applying QFD. Reference [31] employed QFD methodology to translate customer needs and requirements into the quality characteristics to improve quality for an existing product to develop a new consumer product. Reference [32] has presented the differences between the use of QFD and its association with CVCA tool in the development of a CPM device for elbow and forearm rehabilitation. Reference [33] has analyzed programming tools for the development of QFD software. Reference [34] has emphasized the importance of utilizing QFD in selecting technical solution alternatives based on customer voice. The approach also integrated several quality tools and graphical techniques into the standard QFD approach. Reference [35] developed a novel fuzzy multi-criteria group decision making approach integrating QFD, Fuzzy Weighted Average (FWA) and Data 
Envelopment Analysis (DEA) for supplier selection. Reference [36] applied integrated QFD for dry bulk terminal improvement from the perspectives of the customers. Reference [37] has introduced a methodology and procedure for the development of medical healthcare products and services. Reference [38] has presented a case study on Transfo Company wherein they proposed the use of fuzzy QFD and Theory of Inventive Problem Solving (TRIZ) for improving the efficiency in product design. Reference [39] has set up a conceptual design of a future mobile or portable healthcare device using the QFD with the Analytic Network Process (ANP) and TRIZ. They proposed a three-stage QFD in order to consider customers' requirements, extend the whole design process, and calculate the priorities of the left-hand-side elements in HOQ by implanting ANP. Reference [40] has proposed integrated approach that includes AHP, QFD and Linear Physical Programming (LPP) to maximize overall customer satisfaction under uncertain conditions and apply them in the supplier development problem. Reference [41] has carried out a literature review on QFD and software engineering. Reference [42] has proposed a solution in form of an approach which integrates Extreme Programming (EP) and QFD to improve the requirement elicitation process that helps to prioritize the user stories and categorize the risk involved with the user stories.

\section{QFD and Websites Designing}

QFD is widely used customer driven technique that has been recently used in website designing. It provides a structured way to prioritize features, functions or even website content by taking into account both business priorities (the voice of the company) and the customer/user priorities (the voice of the customer) [43]. Reference [44] proposed the enhancement of web design quality through the QFD approach. Reference [11] demonstrated through a case study an application of QFD in redesigning the website. Reference [43] presented an example of B2B website redesign for an Electronics company. Reference [44] in his dissertation reviewed the documented attempts of applying QFD to software/web development. Reference [45] addressed the impact of website design features on Internet browsing and purchase behavior by developing an integral design framework based on QFD. Reference [46] has presented a case study for measuring website quality improvements. Reference [47] in his dissertation investigated the issues of quality control and human factors in a web design context. QFD is employed to bring a human factors engineering perspective to web quality design. Reference [48] investigated electronic commerce services from a quality management perspective. They proposed a novel quality management approach that is based on human factors engineering to manage e-commerce service quality and operate according to customer needs.

\section{Websites Designing and Online Shopping Websites}

Conceptual understanding of the term website designing in online shopping has been presented in the literature by various researchers which provide a base of study for the development of the model in this context. The need for application of fuzzy QFD has been studied and answered by way of some quality management practices. Website design is obviously a multidimensional construct [49]. Many scholars have already grouped website design characteristics into different categories [50] [51] [52]. Web design can be categorized into three categories as - visual design, social cue design and content design. 'Visual design' is defined as graphical and structural factors that give consumers a first impression. 'Social cue design' comprises social cues such as face-to-face interaction and social presence, embedded into the web interface via different communication media [53]. Finally, 'content design' consists of informational components of the website, either textual or graphical [54]. Website effectiveness depends on several factors like - its easeof-use navigation, content and design of usability features and acceptable loading time for 
the site to appear on the screen. The real challenge is to identify and develop design factors that can make a website usable and serviceable, avoiding users frustration or dissatisfaction and create more stimulating, visually pleasing, comprehensive and commercially viable websites [55]. Reference [56] have explored automated approaches for helping designers improve their sites and created an interactive tool that helps steer occasional web site builders away from bad designs and toward better ones. Reference [57] presented findings from a field study undertaken in a web-development company. Reference [58] has introduced the concordance analysis approach to evaluate the ecommerce web sites, and established the comprehensive evaluation model. Reference [59] discussed in his study the usability issues in web site design. Reference [60] has focused on the challenge for the Web development organizations to help organizations finding and characterizing target groups for web sites and to create web applications that can be used to communicate certain information and values to these specific target groups. Reference [61] reported on the evaluation of wireless Internet news sites using the WebQual $/ \mathrm{m}$ instrument. Reference [6] explored the factors associated with web site success in the context of electronic commerce. Reference [62] examined the domain of World Wide Web (WWW) site development and proposed a methodology to assist with this process. Reference [63] has attempted to analyze information evaluation concept and processbased on some quality management concepts, tools and methods in order to propose some basic criteria to evaluate website quality and to select suitable websites.

Reference [64] investigated the results of success of B2C websites in Arab country. They discovered that for the proposed research model gender is a vital aspect. Reference [65] studied various factors and found that factors such as emotional factors; societal factors affect the consumers' attitudes of online buying. Reference [3] has presented a study on ecommerce and online shopping. Reference [66] put forth the influencing and preventing factors of online shopping in China. They increase the influencing factor and demonstrated the factors to influence the online shopping by pragmatic research. Reference [67] suggested that comparison shopping tools depends on consumers' comparison shopping proneness, which in turn is influenced by consumer' online decision-making styles. They showed that some consumer decision-making style dimensions influence comparison shopping proneness while others have no influence. Reference [68] analyzed the activities of one million users of the chinese social commerce site Taobao. Reference [69] investigated how different types of online buyers perceive websites differently. They found that website design, website reliability/fulfillment, website customer service and website security/privacy are the four dominant factors which influence consumer perceptions of online purchasing. Reference [70] presented QFD so that the technical and management requirements could be examined as part of systematic 3-step process that implements e-commerce in a corporation.

\section{QFD in Online Shopping Websites Designing}

Reference [2] proposed an application of QFD to improve the quality of internet shopping website interface design. The authors employed a B2C shopping website as an example in this study. The authors utilized QFD to gain an understanding of customer quality needs, quality elements, and the relationship between them followed by suggestions for improving the quality of website design and discussion on the main performance indices. Reference [71] tried to construct an e-commerce web site quality model from the users' quality requirement, based on total quality management theory and tools. Reference [17] applied QFD for effective website design through an application of e-store design. He has highlighted how an e-store can be designed using QFD and HOQ methodologies. At the end he suggested some e-store design recommendations that would enable the e-store designer to deliver a higher level of e-customer satisfaction. Reference [12] presented a QFD approach to website development for electronic retailing where in 
they have addressed the issue of capturing and integrating "the voice of the customer" into the development process of a web site, by applying the QFD methodology. Furthermore, they demonstrated considering electronic retail sites as a case field as to how QFD can be utilized as an effective tool for guiding design decisions for web sites. QFD has been successfully applied in numerous areas and time and again it applications are reported. However, the crisp nature of QFD and involved subjectivity act as weak link which can be resolved using fuzzy integration with QFD. The next section discusses the fuzzy concepts.

\section{Fuzzy Concepts}

Fuzzy logic is an approach to computing based on "degrees of truth" rather than the usual "true or false" (1 or 0) Boolean logic on which the modern computer is based. The idea of fuzzy logic was first advanced by Dr. Lofti Zadeh in the 1960s. It deals with imprecise data and handle imprecision. Some work has been reported in this area [72]. Reference [73] used fuzzy for evaluating and forecasting danger in accidents. Reference [74] described the design of a room temperature and humidity controller using fuzzy logic. Reference [75] presented a realization of fuzzy-logic hysteresis control of a single phase on-grid inverter. Reference [76] proposed a fuzzy logic technique for the prediction of the risk of breast cancer based on a set of judiciously chosen fuzzy rules utilizing patient age and automatically extracted tumors features. Reference [77] developed a Fuzzy Inference System (FIS) for teaching staff performance appraisal using Matlab. They presented how FIS can be used to build performance evaluation models based on realistic data. Reference [78] showed how fuzzy logic helps in making decision for the estimation of the danger which is related with the software development team. Reference [79] used an Intelligent Wireless Sensor Network (WSN) to monitor the environment of interest and empowered each sensor node by fuzzy logic system to monitor environment, so that a sensor is in sleep mode when there is no data to transmit. Reference [80] offered and introduced fuzzy logic systems which can be successfully applied in multi-agent security paper assessment information system in order to help various investors to manage investment portfolio successfully. Reference [81] proposed an independent routine controller for Unmanned Aerial Vehicles (UAVs) using fuzzy logic to control the speed, altitude and the route of air vehicle. Fuzzy concepts have been successfully applied to handle the uncertainty and vagueness involved in the process. In the same vein, it can be applied in QFD too.

\section{Fuzzy QFD}

As QFD exercises on linguistic expressions and crisp values, fuzzy concepts have to be employed to deal with the uncertainty and vagueness involved. Reference [82] have proposed an approach for manufacturing strategy development based on QFD and integrated fuzzy set theory and HOQ in order to provide a structural tool to capture the inherent imprecision and vagueness of decision-relevant inputs and to facilitate the analysis of decision-relevant QFD information. Reference [83] proposed combination of fuzzy logic with HOQ into QFD for the creation of the eco-friendly product. Reference [40] used a set of fuzzy data to address linguistic values parameterized by triangular fuzzy numbers. They have included AHP, QFD and LPP to maximize overall customer satisfaction under uncertain conditions and apply them in the supplier development problem. Reference [84] tried to dwell on to the problem of identifying the most important 'Quality and Popularity contributing factors', which plays an important role in deciding the 'Popularity' of a TV production. They have explained how a quality plan can be determined for a proposed TV program 'A' by using fuzzy QFD technique. They determined the requirement weights as a range rather than a crisp value. Reference [85] showed how QFD approach can be combined with fuzzy logic to resolve some of 
drawbacks of QFD and proposed fuzzy linguistic approach. And then compared these two approaches to know which applies the best for the case study. Reference [86] has redefined AHP method under fuzziness and then applied QFD process to identify and rank customer's need and translate them into service specification and then did sensitive analysis to make the process more robust from the characterization of integration of the fuzzy AHP and QFD. Reference [87] have presented a fuzzy QFD for determining which of the nonfunctional requirements are important to company's software selection decision based on and integrated with its functional requirements. Reference [88] have identified the e-learning design requirements and selected the most suitable e-learning service provider. They employed fuzzy logic-based QFD for the selection of the e-learning service providers. Reference [89] have examined the implementation of QFD under a fuzzy environment and developed corresponding procedures to deal with the fuzzy data. They examined the sensitivity of the ranking of technical characteristics to the defuzzification strategy and the degree of fuzziness of fuzzy numbers. Reference [90] has presented a fuzzy multiple objective programming approaches that incorporate imprecise and subjective information inherent in the QFD planning process to determine the level of fulfillment of design requirements. Reference [8] has proposed fuzzy scoring for linguistic terms for low-end digital camera whose results showed that fuzzy QFD model can reflect the certainty level of an evaluation term, which is designated for each correlation of customer requirements and technical requirements considered in design. Fuzzy QFD has long been effectively used in other areas and thus fuzzy QFD integration is highly asked for in the designing of online shopping websites.

\section{Findings and Implications}

It is very important to come up with better website designs to satisfy customer quality needs, however, one first needs to understand these needs. This can be done by identifying customer quality needs, to find quality elements, and then to ascertain the relationship between customer needs and quality elements [2]. Moreover, web development like any software development process involves decision making at various stages of the process. Design decisions strongly relate to effective web development. QFD is decision support tool that can effectively guides in design decision. Thus, QFD can be better employed in the designing of online shopping websites. QFD methodology provides a way to translate conceptual requirements into items that are workable, measurable, and capable of design enhancement. The result is a better design, shorter development cycles, better quality and lower costs [8]. Albeit QFD can generate better results but it suffers from the problem like - use of linguistic expressions and crisp values. The QFD process requires various inputs which are also in the form of linguistic data that is quite vague and subjective [7]. Although the quality can be dramatically improved through a QFD exercise, the traditional crisp scoring approach has a major drawback. A wrong conclusion can be easily produced since the fuzzy nature of linguistic correlation terms from evaluation members is ignored. These crisp values cannot reflect the imprecision or vagueness and yields inconsistency in the results [8]. This issue can be resolved using a soft computing technique. Fuzzy set theory is one of the widely used techniques that can better address this issue. It exhibits some useful features for exploitation in QFD. Various inputs, in the form of judgments and evaluations are needed in the QFD charts. Normally, these inputs are gathered through questionnaires, deep interviews, and focus groups. This gives rise to uncertainties when trying to quantify the information. Fuzzy concepts can be used, in order to reduce the uncertainty and vagueness of the collected data. The use of fuzzy-QFD has long been reported by researchers and it has proven more effective. Thus, the need of fuzzy-QFD implementation strongly exists in designing of online shopping websites. 


\section{Conclusion}

The recent innovation in technologies has made online shopping emerged as a rising new trend. However, despite the boom in online shopping, the rate of users' satisfaction has gone down due to poor and inappropriate design of websites. Thus there exists a pressing need for some technique that could help in effective design of websites. A pool of methods have been proposed and reported by researchers in the past but even though they assist in web design they failed to handle the decision making involved in the process.

This paper, thus considers QFD approach as it is a customer oriented process that strongly aids in guiding the design decision efficiently. The purpose of this paper is to explore the issues, analyze the problems with the existing methods and propose effective solution through the literature review. The paper makes the following contributions. First, it explores QFD at length and evaluates its applicability for effective design of online shopping websites. This helps users understand the decision making capabilities of QFD. Through the study, the paper highlights the limitations of QFD approach in handling the vague and imprecise data that arise due to the crisp approach and inherent subjectivity involved in the QFD approach leading to inconsistency in results.

Finally, the paper proposes fuzzy integration with QFD to deal with the uncertainty and vagueness involved in the QFD process as fuzzy set theory is powerful technique to capture the uncertainty and vagueness resulting in improved decision making and more precise results. The study will help designers to become more efficient in making improvements to their designs and in carrying out effective design of online shopping websites.

\section{References}

[1] Deepali, "Study on Growth of Online Shopping in India", International Journal of Computer Science and Mobile Computing, vol. 2, no. 6, (2013), pp. 65-68.

[2] H. M. Kuo, and C. Chen, "Application of Quality Function Deployment to Improve the Quality of Internet Shopping Website Interface Design", International Journal of Innovative Computing, Information and Control ICIC International, vol. 7, no. 1, (2011), pp. 253-268.

[3] A. Sharma, "A Study on E-Commerce and Online Shopping: Issues and Influences", International Journal of Computer Engineering and Technology (IJCET), (2013), pp. 364-376.

[4] H. M. Kuo, "Discussion of the Interfering Factors for Internet Shopping" Conference on Theories and Practices in International Business. Chang Jung Christian University, (2006).

[5] T. Johnson, and D. Griffith, "5 steps to online success", Marketing Management, vol. 11, (2002), pp. 34-39.

[6] Liu and Arnett, "Exploring the Factors Associated with Web Site Success in the Context of Electronic Commerce", Information and Management, Elsevier Science, vol. 38, (2000), pp. 23-33.

[7] Y. Chen, R. Y. K. Fung, and J. Tang, "Rating Technical Attributes in Fuzzy QFD By Integrating Fuzzy Weighted Average Method and Fuzzy Expected Value Operator", European Journal of Operational Research, vol. 174, (2006), pp. 1553-1566.

[8] M. C. Lin, C. Y. Tsai, C. C. Cheng, and C. A. Chang, "Using Fuzzy QFD for Design of Low-End Digital Camera", International Journal of Applied Science and Engineering, vol. 2, (2004), pp. 222-233.

[9] E. Huizingh, "The Antecedents of Website Performance", European Journal of Marketing, vol. 36, (2002), pp. 1225-1247.

[10] R. Kalakota, and A. B. Whinston, "Frontiers of e-commerce", Addison Wesley Longman Publishing Co., Inc., (1996).

[11] R. Islam, M. Ahmed, and M. Hj Alias, "Application of Quality Function Deployment in Redesigning Website: A Case Study on TV3", International Journal of Business Information Systems, vol. 2, no. 2, (2007), pp. 195-216.

[12] G. Ioannou, K. C. Pramatariset, and G. P. Prastacos, "A Quality Function Deployment Approach to Web-Site Development: Applications for Electronic Retailing” Management Technology, vol. 13, no. 3, (2004).

[13] P. Vora, "Human Factors Methodology for Designing Web Sites", Human Factors and Web Development: Erlbaum Publishers, (1997).

[14] J. H. Roh, C. Romano, and J. Ratner, "Roles, Organization, and Support: Building Usability into the Design Process", In Human Factors and the Web, Designing for the Web: Practices and Reflections, Denver, Colorado, USA, (1997). 
[15] C. Alarcon, F. Medina, and R. Villarroel, "Finding usability and communicability problems for transactional web applications", Latin America Transaction, IEEE, vol. 12, no. 1, (2014), pp. 23-28.

[16] T. Chauhan, P. Dalal, and S. Rathore, "Analyzing the Experience of Online Users using B2C Websites", International Journal of Modern Communication Technologies and Research, vol. 2, no. 1, (2014), pp. 9-11.

[17] S. Barutchu, "Quality Function Deployment in Effective Website Designs: An Application in E-Store Design”, vol. 7, no. 1, (2006), pp. 41-63.

[18] Y. Akao, Quality function deployment: integrating customer's requirements into product design. Cambridge. MA: Productivity Press, (1990).

[19] A. Lockamy, and A. Khurana, "Quality Function Deployment: Total Quality Management for New Product Design", International Journal of Quality and Reliability Management, vol. 12, no. 6, (1995), pp. 73-84.

[20] L. Cohen, "Quality function deployment: how to make QFD work for you” J. W Wesner (Ed), Reading, MA: Addison-Wesley Publishing Company. Computers and Industrial Engineering. vol. 35, no. 1-2, (1995), pp. 233-236.

[21] J. R. Hauser, and D. P. Clausing, "The House of Quality", Harvard Business Review, vol. 66, no. 5-6, (1988), pp. 63-73.

[22] A. Griffin, "Evaluating QFD's use in U.S. firms as a process for developing products", Journal of Product Innovation Management, vol. 9, no. 3, (1992), pp. 171-187.

[23] L. Chan, and M. Wu, "A Systematic Approach to Quality Function Deployment with A Full Illustrative Example”, Omega, vol. 33, no. 2, (2005), pp. 119-139.

[24] E. Bulut, S. Huang, and O. Duru, "A multi-variate QFD design for the service quality assessment of kensai International Airport-Japan”, (2013).

[25] Y. Cao, "Software Process Improvement Framework Based on CMMI Continuous Model Using QFD", IJCSI International Journal of Computer Science Issues, vol. 10, no. 3, (2013).

[26] A. K. Sharma, S. A. Sharma, N. Agrawal, and S. Panjwani, "Evaluation Of Software Process Model for The Quality Function Deployment Software", International Journal of Software Engineering and Technology, Coimbatore Institute of Information Technology (CIIT), vol. 3, no. 7, (2013).

[27] M. Sadiq, J. Ahmad, A. Rahman, R. Suman, and S. Khandelwal, "More On Adding Threat During Software Requirements Elicitation And Prioritization", IACSIT International Journal of Engineering and Technology, vol. 2, no. 3, (2010).

[28] A. Alemam, and S. Li, "Integration of Quality Function Deployment and Functional Analysis for Ecodesign”, International Journal of Mechanical Engineering and Mechatronics, vol. 2, no. 1, (2014).

[29] N. Gwangwava, and S. Mhlanga, "Automation of QFD an E Learning Tool for Product Development with an Integrated Product Data Management Platform in E Business", International Journal of eEducation, e-Business, e-Management and e-Learning, vol. 1, no. 5, (2011).

[30] B. L. Tan, N. K. H. Tang, and P. L. Forrester, "Application of QFD for E-Business Planning”, (2007).

[31] S. Zaim, and M. Sevkli, "The Methodology of Quality Function Deployment with Crisp and Fuzzy Approaches and an Application in the Turkish Shampoo Industry", Journal of Economic and Social Research, vol. 4, no. 1, (2000), pp. 27-53.

[32] R. L. Z. Tanure, A. M. Callegaro, and A. S. Buss," Differences between Quality Function Deployment Application and Its Association to Costumer Value Chain Analysis to Development of the CPM Equipment”, (2014).

[33] A.K. Sharma, J. R. Sharma, and I. C. Mehta, "Analyzing Programming Tools for the Development of Quality Function Deployment Software", International Journal of Information and Decision Sciences, Inderscience Publishers, vol. 2, no. 2, (2010), pp. 132-146.

[34] R. Aomar, , J. Dhanhani, , and S. Ali, "An Enhanced QFD Approach for Improving Water Tanks Sustainability at a Local Water Distributor", Industrial Engineering and Management, (2013).

[35] E. E. Karsak, and M. Dursun, "An Integrated QFD-DEA Framework with Imprecise Data for Supplier Selection”, In World Congress on Engineering, vol. 1, (2013), pp. 3-5.

[36] M. A. Razik, R. M. Tahar, W. H, Mahmood, and N. Rozar, "Integrated Quality Function Deployment (QFD) Model for Dry Bulk Terminal Improvements (DBTI) in Malaysian Ports”, Journal of Economics, Business and Management, vol. 3, no. 4, (2013).

[37] S. Khare, and J. Sharma, "From Conception To Creation - Quality Function Deployment In Health Sector", Mathematics and Computers in Contemporary Science.

[38] H. Farsijani, and A. M. Torabandeh, "Improvement of Efficiency in Product Designing by Usage of Fuzzy QFD and Triz: A Case Study on Transfo Company", Journal of Applied Science and Agriculture, vol. 8, no. 4, pp. 451-461.

[39] S. H. Shih, and H.S. Chen, "A Conceptual Design of a Mobile Healthcare Device-An Application of Three-stage QFD with ANP and TRIZ", International Journal of Operations Research, vol. 10, no. 2, (2013), pp. 80-91.

[40] Z. Shad, E. Roghanian, and F. Mojibian, "Integration of QFD, AHP, and LPP Methods in Supplier Development Problems under Uncertainty”, Journal of Industrial Engineering International, (2014). 
[41] A.K. Sharma, I. C. Mehta, S. A. Sharma, D. Sharma, and P. M. Bapat, "Quality Function Deployment and Software Engineering - A Literature Review", Journal of Computer Technology and Applications (JoCTA), STM Publishers, vol. 3, no. 1, (2012), pp. 49-57.

[42] N. Nayar, S. T. Angra, and K. S. Bansal, "Improving the Requirement Elicitation Process in Extreme Programming: The QFD Approach", International Journal of Advanced Research in Computer Science and Software Engineering, vol. 3, no. 6, (2013).

[43] J. Sauro, "Prioritizing UI Improvement: The QFD", (2013), Retrieved August 24, 2014, from http://www.measuringusability.com/blog/qfd-ui.php.

[44] M. O. H. Saeed, Web Development using Quality Function Deployment, M.S.c. Information Systems Thesis, (2004).

[45] J. Hamilton, "Integrating Web Site Design Features For 'One-On-One' Marketing: A QFD Framework", In 7th International Conference on ISO 9000 and TOM (7-ICIT), (2002).

[46] S. J. Barnes, and R. Vidgen, "Measuring Web Site Quality Improvements: A Case Study of the Forum on Strategic Management Knowledge Exchange", Industrial Management and Data Systems, vol. 103, no. 5, (2003), pp. 297-309.

[47] D. Liu, Web Design using A Quality Function Deployment Methodology, University of Nebraska Lincoln, (2002).

[48] W. Zuo, , Q. Huang, C. Fan, and Z. Zhang, "Quality management of B2C e-commerce service based on human factors engineering", Electronic Commerce Research and Applications, vol. 12, (2013), pp. 309320.

[49] S. Kim, and L. Stoel, “Apparel Retailers: Website Quality Dimensions and Satisfaction”, Journal of Retailing and Consumer Services, vol. 11, no. 2, (2004), pp. 109-17.

[50] F. B., Tan, L. L. Tung, and Y. Xu, "Study of Web-Designers' Criteria For Effective Business-ToConsumer (B2C) Websites Using The Repertory Grid Technique", Journal of Electronic Commerce Research, vol. 10, no. 3, (2009), pp. 155-177.

[51] M. Tarafdar and J. Zhang, "Analysis of Critical Website Characteristics: A Cross-Category Study of Successful Websites", Journal of Computer Information Systems, vol. 46, no. 2, (2006), pp. 14-24.

[52] P. Zhang, G. M. Dran, P. Blake, and V. Pipithsuksunt, "Important Design Features in Different Web Site Domains: An Empirical Study of User Perceptions". E-Service Journal, vol. 1, no. 1, (2001), pp. 77-91.

[53] F. P. Karimov, M. Brengman, and L. P. Hove, "The Effect of Website Design Dimensions on Initial Trust", Journal of Electronic Commerce Research, vol. 12, no. 4, (2011), pp. 272-301.

[54] Y. D. Wang, and H. H. Emurian, "An Overview of Online Trust: Concepts, Elements and Implications", Computers in Human Behavior, vol. 21, no. 1, (2005), pp. 105-125.

[55] P. Zhang, and G. M. Von Dran, "Satisfiers and Dissatisfiers: A two factor model for website design and evaluation", Journal of the American society for information science, vol. 51, no. 14, (2000), pp. 12531268.

[56] M. Y. Ivory, and M. A. Hearst, "Improving Web Site Design”, IEEE Internet Computing, (2002).

[57] P. H. Carstensen and L. Vogelsang, "Design of Web-based Information Systems - New Challenges for Systems Development?” In 9th European Conference on Information Systems, Bled, Slovenia, (2001), pp. 536-547.

[58] C. Jinling, "Comprehensive Evaluation of E-Commerce Web Site Based on Concordance Analysis", IEEE International Conference on e-Business Engineering, (2005), 12-18, Beijing.

[59] N. Bevan, "Usability issues in web site design", In HCI, vol. 2, (1997), pp. 803-806.

[60] L. Vogelsang, "User Involvement in Development of Web Based Publishing", In 11th European Conference on Information Systems, CD-Rom, Naples Italy, (2003).

[61] S. J. Barnes, K. Liu, and R. T. Vidgen, "Evaluating wap news sites: the webqual $/ \mathrm{m}$ approach", In 9th European Conference on Information Systems Bled, Slovenia, (2001).

[62] D. Howcroft, and J. Carroll, "A proposed methodology for web development”, ECIS, (2000).

[63] N. G. Dragulanescu, "Website Quality Evaluations: Criteria and Tools", the International Information and Library Review, (2002).

[64] K. Rouibah, "E-Shopping Success Dimensions: An Empirical Study in Kuwait", In Industrial Engineering and Operations Management Bali, Indonesia, (2014).

[65] S. Nazir, A. Tayyab, A. Sajid, H. Rashid, and I. Javed, "How online shopping is affecting consumers buying behavior in Pakistan?", IJCSI International Journal of Computer Science Issues, vol. 9, no. 1, (2012).

[66] N. Wang, D. Liu, and J. Cheng, "Study on the Influencing Factors of Online Shopping", In 11th Joint Conference on Information Sciences, (2008).

[67] Y. Park, and U. Gretzel, "Influence of Consumers' Online Decision-Making Style on Comparison Shopping Proneness and Perceived Usefulness of Comparison Shopping Tools", Journal of Electronic Commerce Research, vol. 11, no. 4, (2010).

[68] S. Guo, M. Wang, and J. Leskovec, "The role of social networks in online shopping: information passing, price of trust, and consumer choice", In Proceedings of the 12th ACM conference on Electronic commerce, ACM, (2011). 
[69] G. S. Shergill, and Z. Chen, "Web-Based Shopping: Consumers' Attitudes towards Online Shopping in New Zealand", Journal of Electronic Commerce Research, vol. 6, no. 2, (2005).

[70] M. A. Shaikh, A. H. Al-Badi, , A. H. Al-Elaiwi, A. Al-Ameri, and J. A. Whittaker, "E-Commerce Need Analysis via Quality Function Deployment", In Change Management and the New Industrial Revolution, 200. IEMC '01 Proceedings, (2001).

[71] C. Jinling, S. Tong, L. Chuncan, and S. Tao, "Modeling E-Commerce Website Quality with Quality Function Deployment" IEEE International Conference on e-Business Engineering, (2009).

[72] A .K. Sharma, and B. V. Padamwar, "Fuzzy Logic Based Systems in Management and Business Applications", International Journal of Innovative Research in Engineering and Science, vol. 1, no. 2, (2013).

[73] J. Naieni, A. Makui, and R. Ghousi, “An Approach for Accident Forecasting Using Fuzzy Logic Rules: A Case Miningo Lift Truck Accident Forecasting in One of The Iranian Car Manufacturers", International Journal of Industrial Engineering and Production Research, vol. 23, no. 1, (2012).

[74] T. K. Das, and Y. Das, "Design of a room temperature and humidity controller using fuzzy logic", American Journal of Engineering Research (AJER), vol. 2, no. 11, (2013), pp. 86-97.

[75] M. Tomova, Antchev, and M. Petkova, "Fuzzy Logic Hysteresis Control of A Single-Phase on-Grid Inverter: Computer Investigation", International Journal of Power Electronics and Drive System (IJPEDS), vol. 3, no. 2, (2013), pp. 179-184.

[76] V. Balanica, I. Dumitrache, and M. Caramihai, "Evaluation of Breast Cancer Risk By using Fuzzy Logic". U.P.B. Sci. Bull. Series, vol. 73, no. 1, (2011).

[77] G. A., Bhosale, and R. S. Kamath, "Fuzzy Inference System for Teaching Staff Performance Appraisal", International Journal of Computer and Information Technology, vol. 2, no. 3, (2013).

[78] S. Kaur, and R. Goyal, "Fuzzy logic based decision support system for poor team cohesiveness", International Journal for Science and Emerging Technologies, (2012).

[79] M. R. Tripathy, S. Sharma, K. Gaur, and G. S. Virdi, "Energy Efficient Fuzzy Logic Based Intelligent Wireless Sensor Network" Progress in Electromagnetic Research Symposium, Cambridge, (2010).

[80] Jurgutis, and R. Simutis, "An Investment Portfolio Management using Software Agents that Rely on Fuzzy Logic and with Different Decision Arguments Combinations", David Publishing, Computer Technology and Application, (2012).

[81] S. Kurnaz, O. Cetin, and O. Kaynak, "Fuzzy Logic Based Approach to Design of Flight Control and Navigation Tasks for Autonomous Unmanned Aerial Vehicle", J Intell Robot System, vol. 54, (2009), pp. 229-244.

[82] G. Z. Jia, and M. Bai, "An Approach for Manufacturing Strategy Development Based On Fuzzy-QFD". Journal Computers and Industrial Engineering, vol. 60, (2011).

[83] P. Pusporini, K. Abhary, and L. Luong, "Integrating Environmental Requirements into Quality Function Deployment for Designing Eco-Friendly Product", International Journal of Materials, Mechanics and Manufacturing, vol. 1, no. 1, (2013).

[84] S. Prakash, and M. Darbari, "Quality and Popularity Prediction Modeling of TV Program through Fuzzy QFD Approach", Journal of Advances in Information Technology, vol. 3, no. 2, (2012).

[85] R. U. Sundar, "Application of Quality Function Deployment Method and Fuzzy Logic for Improving the Design Characteristics in FRP Cooling Tower-Case Study", International Journal of Engineering Science and Technology (IJEST), vol. 4, (2012).

[86] T. Bakshi, B.Sarkar, and S. Sanyal, "A Novel Integrated AHP-QFD Model for Software Project Selection under Fuzziness", International Journal of Computer Applications, vol. 54, no. 7, (2012).

[87] C. G. Sen and H. Baracli, "Fuzzy quality function deployment based methodology for acquiring enterprise software selection", Expert Systems with Applications, vol. 37, (2010).

[88] Y. Kazancoglu, and M. Aksoy, "A Fuzzy Logic- Based Quality Function Deployment for Selection of E-Learning Provider", TOJET: The Turkish Online Journal of Educational Technology, vol. 10, (2011).

[89] X. X. Shen, K. C. Tan, and M. Xie, "The Implementation of Quality Function Deployment based on Linguistic Data", Journal of Intelligent Manufacturing vol. 12, (2010), pp. 65-75.

[90] E. E. Karsak, "Fuzzy Multiple Objective Programming Framework to Prioritize Design Requirements in Quality Function Deployment", Computers and Industrial Engineering, vol. 47, no. 2-3, (2004), pp. 149-163.

\section{Authors}

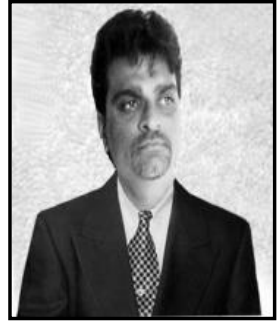

Ashish K. Sharma. He is presently working as an Asst. Prof. in Manoharbhai Patel Institute of Engineering and Technology (MIET), Gondia, India. Prior to this, he was associated with IT industry in the areas of Training, Software and Web Application Development. He has an experience of more than 16 years in Academic, Industrial and Software Development field. He is a Microsoft Certified Professional $(M C P)$ and also holds Brainbench Certification. He has more than 15 
research papers and articles published Nationally and Internationally in various reputed Journals and Conferences to his credit which includes TnFOnline, Inderscience and Actapress Journals. He is an Approved Supervisor of Nagpur University for M.E. by Research in Computer Science and Technology. His thrust areas include Software Engineering, Software and Web Development, Databases, Data Mining, Image Processing, Windows Forensics, Fuzzy Logic etc.

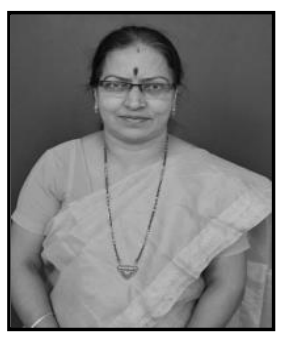

Sunanda P. Khandait. She is presently working as a Professor and Head in IT department of KDK college of Engineering, Nagpur, India. She has a rich experience of more than 22 years. She has published more than 30 research papers in credit in National and International Journals and Conferences. She has also published a couple of Book Chapters. She is an Approved Supervisor of Nagpur University for PhD in Computer Science and Technology. Her thrust areas include Databases, Image Processing, Pattern Analysis and Recognition, Data Processing and Mining, Fuzzy, Neural Network etc. 
International Journal of Hybrid Information Technology Vol.9, No.4 (2016) 